\title{
Long-term outcomes after surgical dissection of inguinal lymph node metastasis from rectal or anal canal adenocarcinoma
}

Taro Tanabe ${ }^{1}$, Dai Shida ${ }^{1 *}$, Sho Komukai ${ }^{2}$, Yuya Nakamura ${ }^{1}$, Shunsuke Tsukamoto ${ }^{1}$ and Yukihide Kanemitsu ${ }^{1}$

\begin{abstract}
Background: The 8th edition of the tumor-node-metastasis (TNM) classification classifies inguinal lymph nodes as regional lymph nodes for anal canal carcinoma but non-regional lymph nodes for rectal carcinoma. This difference might reflect the different prognosis of inguinal lymph node metastasis from anal canal carcinoma and rectal carcinoma. However, long-term outcomes of inguinal lymph node metastasis from rectal or anal canal adenocarcinoma are unclear, which we aimed to investigate in this study.

Methods: The study population included 31 consecutive patients with rectal or anal canal adenocarcinoma who underwent inguinal lymph node dissection with curative intent at the National Cancer Center Hospital from 1986 to 2017. Long-term outcomes were assessed and clinicopathologic variables analyzed for prognostic significance.

Results: Of the 31 patients, 12 patients had rectal adenocarcinoma and 19 patients had anal canal adenocarcinoma. Synchronous metastasis were observed in 14 patients and metachronous metastasis in 17 patients. After dissection of inguinal lymph node metastasis with curative intent, the 5-year overall survival rate was 55.2\%, with 12 patients surviving for more than 5 years. Median survival time was 66.6 months. Multivariate analyses revealed that location of primary tumor (rectum versus anal canal) was not a prognostic factor, whereas lateral lymph node metastasis and histological findings were independent prognostic factors.
\end{abstract}

Conclusion: Given the good prognosis, inguinal lymph node metastasis in patients with rectal or anal canal adenocarcinoma appears to be regional rather than distant. If R0 resection can be achieved, inguinal lymph node dissection may be indicated for these patients.

Keywords: Inguinal lymph node metastasis, Rectal cancer, Anal canal cancer, Inguinal lymph node dissection, NCCN guidelines, TNM classification

\section{Background}

Anal canal cancer is the most common type of gastrointestinal malignancy that metastasizes to inguinal lymph nodes (LNs). Whereas inguinal LN metastasis from anal canal cancer is classified as $\mathrm{N} 2$ in the 7th edition of the tumor-node-metastasis (TNM) classification when metastasis is unilateral, or as N3 when metastases are bilateral [1], it is categorized in the 8 th edition as

\footnotetext{
* Correspondence: dshida@ncc.go.jp

${ }^{1}$ Department of Colorectal Surgery, National Cancer Center Hospital, 5-1-1

Tsukiji, Chuo-ku, Tokyo 1040045, Japan

Full list of author information is available at the end of the article
}

N1a (N1a: metastases in inguinal, mesorectal, and/or internal iliac nodes) $[2,3]$. This classification was modified based on accumulating evidence from studies on anal canal squamous cell carcinoma $[4,5]$.

Most anal canal cancer cases in Western countries involve squamous cell carcinoma, which accounts for almost $90 \%$ of these cases [6]. In contrast, adenocarcinoma is the predominant histological subtype of malignancy arising in the anal canal in Asian countries such as Japan and China [7]. Specifically, adenocarcinomas account for $63 \%$ of anal canal cancers in China [8] and 74\% in Japan [7], although anal canal

(c) The Author(s). 2019 Open Access This article is distributed under the terms of the Creative Commons Attribution 4.0 International License (http://creativecommons.org/licenses/by/4.0/), which permits unrestricted use, distribution, and 
cancer itself is a rare disease in these countries. Given the rarity of this disease, little is known about the long-term outcomes of inguinal LN metastasis from anal canal adenocarcinoma. The largest study cohort of patients (21 patients) with inguinal LN metastasis from anal canal adenocarcinoma to date was reported by $\mathrm{Su}$ et al., showing 5 -year overall survival (OS) rate as $19.1 \%$ [8].

Inguinal LNs in rectal carcinoma are classified as nonregional LNs in the TNM classification [2]. Adenocarcinomas that originate from the lower rectum occasionally metastasize to inguinal LNs in a manner similar to anal canal cancer, with an incidence of approximately 2.0$4.5 \%[9,10]$. Some studies have reported that inguinal LN metastasis from rectal adenocarcinoma occurs as a consequence of locally advanced primary tumors or recurrent pelvic malignancy, and that in these cases, only systemic chemotherapy and radiotherapy should be considered due to the frequency of distant metastasis and poor prognosis $[9,11]$. Other studies reported that solitary inguinal LN metastasis from rectal adenocarcinoma showed a favorable prognosis after LN excision and thus surgical treatment may be a reasonable therapeutic option for such patients [12, 13]. Accordingly, appropriate treatment strategies for inguinal LN metastasis from rectal adenocarcinoma are unclear, and surgical treatment for inguinal LN metastasis remains controversial.

The TNM 8th edition classifies inguinal LNs as regional LNs for anal canal carcinoma, but non-regional for rectal carcinoma [2]. No study to date has adequately accounted for this difference. Survival is thought to be an adequate indicator for determining regional versus distant metastasis. In this respect, this study aimed to investigate the long-term outcomes, specifically with respect to OS, of inguinal lymph node metastasis from rectal or anal canal adenocarcinoma, which makes it possible to speculate whether inguinal $\mathrm{LN}$ metastasis is regional or distant. In this study, because anorectal adenocarcinoma is sometimes difficult to determine its anatomical origin (rectum or anus) and thus rectal adenocarcinoma and anal adenocarcinoma sometimes overlap, and because treatment strategies for rectal adenocarcinoma and for anal adenocarcinoma are completely same according to the National Comprehensive Cancer Network (NCCN) guidelines 2018 [14, 15] (surgery, and sometimes followed by chemotherapy), and because of the limited sample size, inguinal LN metastasis from these two types was considered as a single entity and the combined data were analyzed.

\section{Methods}

\section{Patients}

Patients with inguinal LN metastasis from rectal or anal canal adenocarcinoma who underwent inguinal LN dissection with curative intent at the National Cancer Center Hospital from September 1986 to August 2017 were included in this study. Patients who had incomplete medical records and those who underwent only biopsy of inguinal LNs for diagnosis were excluded. Patients with inguinal LN metastasis from colon adenocarcinoma and patients with other histological types were also excluded.

The Institutional Review Board (IRB) of the National Cancer Center Hospital approved this retrospective study (IRB code: 2017-437).

\section{Anatomic definition of lower rectum and anal canal tumors}

The TNM classification defines rectal carcinoma and anal canal carcinoma based on the anatomical location of the primary tumor. According to the TNM 8th edition [2], the anal canal begins where the rectum enters the puborectalis sling at the apex of the anal sphincter complex and ends with the squamous mucosa blending with the perianal skin. In the present study, tumor location was determined by colonoscopy and digital rectal examination before surgery. If the center of the tumor was located above the puborectalis sling, the tumor was defined as lower rectal cancer, and when below the puborectalis sling, as anal canal cancer.

\section{Treatment of rectal or anal canal adenocarcinoma in Japan}

Preoperative treatment, including chemoradiotherapy and chemotherapy, prior to total mesorectal excision is the current standard for locally advanced rectal cancer in many Western countries [16]. However, in Japan, surgery with total mesorectal excision plus lateral lymph node dissection (LLND), without preoperative therapy is performed as the standard treatment for rectal cancer [17]. Thus, regardless of the clinical lateral lymph node status, LLND, including prophylactic dissection, without neoadjuvant chemoradiotherapy is usually performed for patients with locally advanced rectal or anal canal adenocarcinomas in Japan.

\section{Inguinal LN metastasis}

All the patients in this study had clinically positive inguinal nodes detected on CT. In most cases, a biopsy of the inguinal LNs was not performed prior to inguinal node dissection. Patients with pathologically positive inguinal nodes were included in this study. Prophylactic inguinal LN dissection was not performed in cases of lower rectum adenocarcinoma or anal canal adenocarcinoma, without clinically positive inguinal nodes. Synchronous inguinal LN metastasis was defined as metastasis occurring within six months after the diagnosis of rectal or anal canal adenocarcinoma. 


\section{Inguinal LN dissection}

Technical details of inguinal LN dissection are described below. At $3 \mathrm{~cm}$ below the inguinal ligament, a slanting incision is made parallel to the inguinal ligament. Reaching above the femoral artery, a $6 \mathrm{~cm}$ incision is made along the femoral artery. Both superficial and deep inguinal LNs, including Cloquet's nodes, are then dissected. After locating the femoral vein, the great saphenous vein is identified. All tissue between the fascia lata and Camper's fascia within the standard template for inguinal node dissection is freed and the great saphenous vein is sacrificed. The inguinal ligament, adductor muscle, sartorius muscle, and the intersection point between these muscles surround the dissection area.

\section{Statistical analysis}

The categorical variables were presented as frequencies, with percentages. Pearson's chi-square test was used to compare categorical variables. The Kaplan-Meier method was used to estimate overall survival (OS) which was defined as the survival probability (in days) from the date of inguinal LN dissection to the date of death from all causes. The survival days were censored at May 1, 2018. We estimated OS for each covariate level, and we evaluated the association with each covariate using the logrank test. The results are shown as median survival and $p$-value. Multivariate Cox proportional hazards regression models with Firth's modification [18], which were used to avoid sparse data bias and related problems, were subsequently fitted to evaluate the factors independently associated with OS. The prediction model was detected based on Akaike information criteria (AIC) from all conceivable models with different sets of covariates [19]. The results of the multivariate analyses were presented as hazard ratios (HRs), together with their 95\% confidence interval (95\% CIs) for the selected prediction model. A probability value of $P<0.05$ was considered statistically significant. All statistical analyses were performed using the JMP13 software program (SAS Institute Japan Ltd., Tokyo, Japan) or $\mathrm{R}$ version 3.5.3 and the 'coxphf' package (R Project).

\section{Results}

\section{Characteristics of the study cohort}

One patient with an incomplete medical record, one patient who underwent a biopsy of an inguinal LN only for diagnostic purposes, and four patients with inguinal LN metastasis attributed to colon adenocarcinomas were excluded, leaving 19 patients with anal canal adenocarcinoma and 12 patients with lower rectal adenocarcinoma as the final study population. The patient characteristics and primary tumor information are summarized in Table 1. Of the 31 patients, 23 patients underwent abdominoperineal resection, six patients underwent pelvic exenteration, and two patients underwent intersphincteric
Table 1 General information on patients and primary tumor $(n=31)$

\begin{tabular}{|c|c|c|}
\hline \multicolumn{2}{|l|}{ Characteristic } & \multirow{2}{*}{$\frac{\text { Case (\%) }}{23(74 \%)}$} \\
\hline Sex & Male & \\
\hline & Female & $8(26 \%)$ \\
\hline \multirow[t]{2}{*}{ Age, years } & $<65$ & $15(48 \%)$ \\
\hline & $\geq 65$ & $16(52 \%)$ \\
\hline \multirow[t]{3}{*}{ Surgical procedure } & $\begin{array}{l}\text { Abdominoperineal } \\
\text { resection }\end{array}$ & $23(74 \%)$ \\
\hline & $\begin{array}{l}\text { Intersphincteric } \\
\text { resection }\end{array}$ & $2(6 \%)$ \\
\hline & Total pelvic exenteration & $6(20 \%)$ \\
\hline \multirow[t]{2}{*}{ Tumor size, $\mathrm{cm}$} & $<5$ & $17(55 \%)$ \\
\hline & $\geq 5$ & $14(45 \%)$ \\
\hline \multirow[t]{2}{*}{ Location } & Rectum & $12(39 \%)$ \\
\hline & Anal canal & $19(61 \%)$ \\
\hline \multirow[t]{4}{*}{ Depth of tumor invasion } & pathological T1 & $3(10 \%)$ \\
\hline & pathological T2 & 7 (23\%) \\
\hline & pathological T3 & $11(35 \%)$ \\
\hline & pathological T4 & $10(32 \%)$ \\
\hline \multirow{2}{*}{$\begin{array}{l}\text { Mesorectal lymph node } \\
\text { metastases }\end{array}$} & Yes & $18(58 \%)$ \\
\hline & No & $13(42 \%)$ \\
\hline \multirow[t]{3}{*}{ Lateral lymph node metastases } & Yes & $12(39 \%)$ \\
\hline & No & $11(36 \%)$ \\
\hline & LLND was not performed & $8(25 \%)$ \\
\hline \multirow[t]{2}{*}{ Distant metastases } & MO & $29(93 \%)$ \\
\hline & M1 & $2(7 \%)$ \\
\hline \multirow[t]{2}{*}{ Histology } & $\begin{array}{l}\text { Well/moderately } \\
\text { differentiated }\end{array}$ & $23(74 \%)$ \\
\hline & $\begin{array}{l}\text { Poorly differentiated/ } \\
\text { mucinous }\end{array}$ & $8(26 \%)$ \\
\hline \multirow[t]{4}{*}{ Pathological Stage } & 1 & $6(19 \%)$ \\
\hline & $\|$ & $2(7 \%)$ \\
\hline & III & $21(67 \%)$ \\
\hline & IV & $2(7 \%)$ \\
\hline
\end{tabular}

LLND lateral lymph node dissection

resection for primary cancer. Thirty patients underwent surgery (total mesorectal excision plus LLND) without any preoperative therapy, and one patient received neoadjuvant chemoradiotherapy. LLND was not performed in eight (26\%) patients for the following reasons: Five of these patients were clinical T1 stage, and the general condition of the other three patients was poor due to severe comorbidities or old age. Histological findings of the primary tumor showed a well- or moderately differentiated adenocarcinoma in 26 patients, poorly differentiated adenocarcinoma in three patients, and a mucinous adenocarcinoma in two patients. In all cases, the surgical margins were negative. 
Clinicopathologic features of inguinal LN metastasis are described below. Median number of retrieved inguinal LNs was 7 (range, 1-22). We observed synchronous metastasis in 14 patients and metachronous metastasis in 17 patients. Two patients with synchronous inguinal LN metastasis also had liver metastasis. Bilateral inguinal LN metastasis was found in five patients. Seventeen patients had only one positive inguinal $\mathrm{LN}$; four patients had two positive inguinal LNs; and 10 patients had more than two positive inguinal LNs. Five of 31 patients received adjuvant chemotherapy, and four patients received adjuvant radiotherapy, after inguinal LN dissection.

Figure 1 shows types of inguinal LN metastasis classified by the presence or absence of mesorectal LN metastasis and lateral LN metastasis. Ten patients had neither mesorectal LN nor lateral LN metastasis (Fig. 1a), 11 patients had mesorectal LN metastasis without lateral LN metastasis (Fig. 1b), three patients had lateral LN metastasis without mesorectal LN metastasis (Fig. 1c), and seven patients had both mesorectal LN metastasis and lateral LN metastasis (Fig. 1d).

\section{Long-term outcomes after inguinal LN dissection}

In the entire cohort, 3- and 5-year OS rates were 76.5 and $55.2 \%$, respectively, with a median follow-up time for survivors of 47.5 months (range, 1.9-276.6 months). Median survival time (MST) was 66.6 months. Notably, 12 patients survived for more than five years (Fig. 2). No significant difference was found between prognosis of anal canal adenocarcinoma with inguinal LN metastasis and that of lower rectal adenocarcinoma with inguinal LN metastasis $(p=0.31)$.

Twenty-five patients experienced recurrence after inguinal LN dissection during the study period; 10 patients had local pelvic recurrence, four patients had inguinal LN recurrence (three on the other side, one on the same side), 11 patients had lung metastasis, three patients had liver metastasis, and one patient had peritoneal dissemination. As for timing of recurrence after inguinal LN dissection, 15 had recurrence within one year, and 10 had recurrence more than one year after inguinal LN dissection. Median relapse-free time was 10.3 months. Recurrence after inguinal LN dissection was treated by a multidisciplinary team approach including surgical resection $(n=4)$, radiotherapy $(n=4)$, chemotherapy $(n=14)$, and a combination of surgical resection and chemotherapy $(n=2)$.

\section{Factors affecting prognosis of inguinal LN metastasis}

The univariate analyses revealed no significant association between the location of the primary tumor (rectum

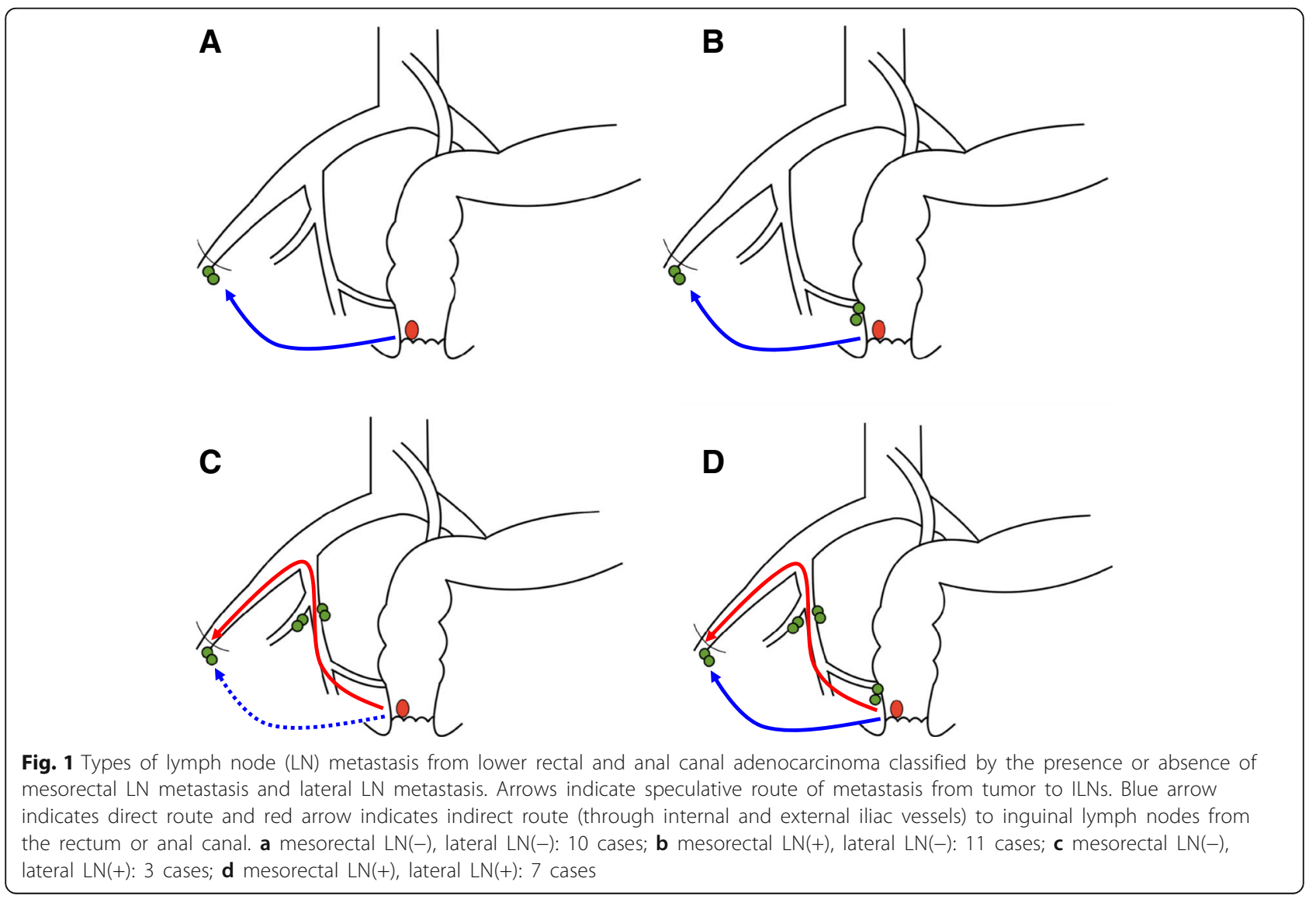




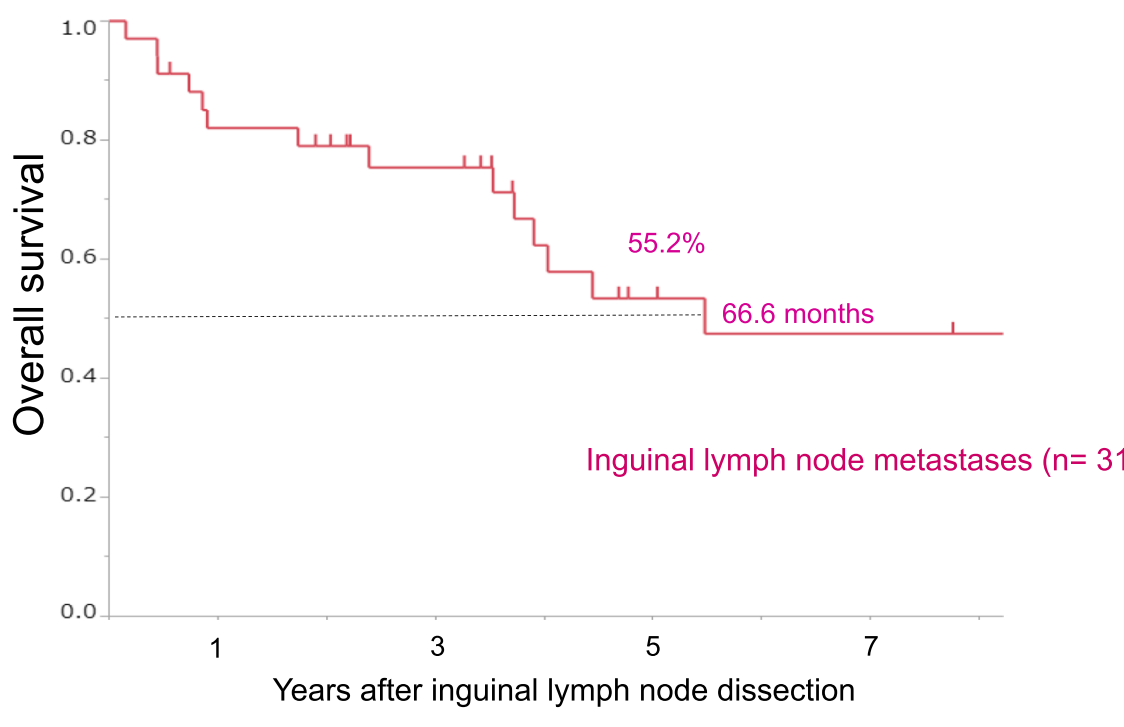

$\begin{array}{lllllllll}\text { No. at risk } & 31 & 25 & 24 & 21 & 16 & 12 & 9 & 9\end{array}$

Fig. 2 Overall survival curves for rectal and anal canal adenocarcinoma patients after inguinal LN dissection for inguinal lymph node metastasis $(n=31)$

versus anal canal) and OS $(p=0.305)$. According to the multivariate analysis with Firth's modification, a model composed of six covariates (see Table 2) was the optimal model based on the AIC from all conceivable models with different sets of covariates. Patients with lateral LN metastasis had a significantly worse prognosis (HR [95\% CI]: 4.476 [1.42-15.28], $p=0.0011$ ). Patients with histological findings of poorly differentiated or mucinous adenocarcinoma also had worse prognosis (HR [95\% CI]: 7.995 [1.61-43.01], $p=0.012)$. In contrast, whereas tumor location, tumor size, presence of mesorectal LN metastasis, and timing of inguinal LN metastasis were selected in the model, these didn't have significant HRs (Table 2). The other variables were not selected as the prognostic factor.

\section{Discussion}

The present study found that, for long-term outcomes after inguinal LN dissection from rectal or anal canal adenocarcinoma with curative intent, MST was 66.6 months and 5-year OS was 55.2\%. These results are noticeably better than previous data reported for inguinal LN metastasis from anal canal or rectal adenocarcinoma (MST, 8-14.8 months; 5-year OS, 0-19.1\%) [8, 9, 11, 20]. This discrepancy could be due to the small sample size in the previous studies $(8-32$ patients) $[8,9,11,20]$, as well as recent developments in chemotherapy and the multidisciplinary team approach. In our study, although almost $80 \%$ of patients experienced recurrence after inguinal LN dissection, a multidisciplinary team approach that included surgical treatment and chemotherapy for recurrent tumors could have led to the better prognosis. Our MST of 66.6 months was also better than those reported for colorectal cancer patients with distant metastasis. According to the Analysis and Research in Cancers of the Digestive System database, MST was 19.3 months in colorectal cancer patients with liver metastasis, 24.6 months in those with lung metastasis, and 16.3 months in those with peritoneal metastasis [21]. Patients who underwent curative resection of liver metastasis, and thus are expected to have a favorable prognosis among stage 4 colorectal cancer patients, had 5-year survival rates of about $40 \%$ $[22,23]$, whereas patients who underwent curative resection of peritoneal metastasis had 5-year survival rates of about $30 \%[24,25]$. Thus, from the perspective of longterm outcomes, inguinal LN metastasis from rectal or anal canal adenocarcinoma appears to be regional rather than distant.

Previous studies have reported that, for rectal or anal canal adenocarcinoma with inguinal LN metastasis, unilateral inguinal LN metastasis, metachronous LN metastasis, and solitary inguinal LN metastasis are independent factors associated with a longer OS $[12,13,20]$. In contrast, we found that the absence of lateral LN metastasis and histological type of well or moderately differentiated adenocarcinoma were independent factors associated with longer OS in patients with inguinal LN metastasis from rectal or anal canal adenocarcinoma.

Lymph drainage at and proximal to the dentate line is directed toward the anorectal, perirectal, and paravertebral nodes and to some extent, the internal iliac system nodes, and lymph drainage below the dentate line mainly is directed to superficial inguinal LNs [26, 27]. There are two lymphatic routes from the rectum to 
Table 2 Univariate and multivariate analyses of factors affecting survival in rectal or anal canal cancer patients with inguinal lymph node metastases

\begin{tabular}{|c|c|c|c|c|c|c|c|}
\hline \multirow[t]{2}{*}{ Variable } & \multirow{2}{*}{\multicolumn{2}{|c|}{ Category }} & \multirow{2}{*}{$\begin{array}{l}\text { Median } \\
\text { overall } \\
\text { survival } \\
\text { (months) }\end{array}$} & \multirow{2}{*}{$\begin{array}{l}\text { Univariate } \\
\text { analysis } p \\
\text { value }\end{array}$} & \multicolumn{3}{|c|}{ Multivariate analysis } \\
\hline & & & & & Hazard ratio & $95 \% \mathrm{Cl}$ & $p$ value \\
\hline \multirow[t]{2}{*}{ Sex } & Male & & 54.1 & 0.160 & & & \\
\hline & Female & & 241.9 & & & & \\
\hline \multirow[t]{2}{*}{ Age, years } & $<65$ & & 120.6 & 0.565 & & & \\
\hline & $\geq 65$ & & 66.6 & & & & \\
\hline \multirow[t]{2}{*}{ Location of primary tumor } & Rectum & & 120.6 & 0.305 & Reference & & \\
\hline & Anal canal & & 54.1 & & 2.01 & $0.65-7.12$ & 0.230 \\
\hline \multirow[t]{2}{*}{ Pathological T stage } & $\mathrm{T} 1,2,3$ & & 66.6 & 0.806 & & & \\
\hline & $\mathrm{T} 4$ & & 121.7 & & & & \\
\hline \multirow[t]{2}{*}{ Tumor size, cm } & $<5$ & & 49.1 & 0.745 & Reference & & \\
\hline & $\geq 5$ & & 121.7 & & 0.51 & $0.16-1.59$ & 0.247 \\
\hline \multirow[t]{2}{*}{ Mesorectal lymph node metastases } & No & & 120.1 & 0.409 & Reference & & \\
\hline & Yes & & 54.1 & & 2.06 & $0.56-7.08$ & 0.262 \\
\hline \multirow[t]{2}{*}{ Lateral lymph node metastases } & No & & 241.9 & 0.025 & Reference & & \\
\hline & Yes & & 45.3 & & 4.48 & $1.42-15.28$ & 0.011 \\
\hline \multirow[t]{2}{*}{ Distant metastases } & MO & & 120.6 & 0.811 & & & \\
\hline & M1 & & 54.1 & & & & \\
\hline \multirow[t]{2}{*}{ Histology } & Well/moderate & entiated & 120.6 & 0.027 & Reference & & \\
\hline & Poorly differen & nucinous & 10.4 & & 7.99 & $1.61-43.01$ & 0.012 \\
\hline \multirow[t]{2}{*}{ Number of positive inguinal LNs } & $<3$ & $(n=21)$ & 121.7 & 0.159 & & & \\
\hline & $\geq 3$ & $(n=10)$ & 51.5 & & & & \\
\hline \multirow[t]{2}{*}{ Site of inguinal LN metastases } & Unilateral & $(n=26)$ & 120.6 & 0.678 & & & \\
\hline & Bilateral & $(n=5)$ & 51.6 & & & & \\
\hline \multirow[t]{2}{*}{ Timing of inguinal LN metastases } & Synchronous & $(n=14)$ & 49.1 & 0.236 & Reference & & \\
\hline & Metachronous & $(n=17)$ & 120.6 & & 0.31 & $0.09-1.03$ & 0.056 \\
\hline
\end{tabular}

Data are presented as median or hazard ratio $(95 \% \mathrm{Cl})$

LN lymph node

inguinal LNs; one is a direct route [9], and the other is an indirect route which passes through internal and external iliac vessels. As shown in Fig. 2, we classified patterns of LN metastasis into four types based on the presence or absence of mesorectal LN and lateral LN metastasis. Figure $2 \mathrm{a}$ and $\mathrm{b}$ show inguinal LN metastasis via the direct route, and Fig. $2 \mathrm{c}$ and $\mathrm{d}$ by the indirect route (though lateral $\mathrm{LNs}$ ), direct route, or both routes. Among the 10 patients with independent inguinal LN metastasis without metastasis to other areas, seven had a relatively small primary tumor $(<5 \mathrm{~cm})$. In contrast, among the 14 patients with a tumor $>5 \mathrm{~cm}, 11$ had mesorectal LN and/or lateral LN metastasis, indicating that large tumors invaded multiple lymphatic routes. According to multivariate analysis, patients with lateral LN metastasis had a poorer prognosis than patients without lateral $\mathrm{LN}$ metastasis. This suggests that inguinal LN metastasis by the indirect route leads to more progressive disease.

The TNM classification defines rectal carcinoma and anal canal carcinoma based only on the anatomical location of the primary tumor, without accounting for histological type. One issue with this is that both adenocarcinoma and squamous cell carcinoma, which originate from the anal canal, are classified in the same category despite their different treatment strategies. Namely, standard treatment for primary anal canal squamous cell carcinoma is chemoradiotherapy $[4,6]$, whereas that for adenocarcinoma is surgery. With regard to squamous cell carcinoma of the anal canal with inguinal LN metastasis, a previous study reported that the 5-year OS in patients with synchronous inguinal LN metastasis was $54.4 \%$, and primary local control in the inguinal area after inguinal LN dissection was 68\% [6]. 
In the present study of rectal and anal canal adenocarcinoma, 5-year OS was $55.2 \%$, which is similar to that reported for anal canal squamous cell carcinoma patients.

This study has some limitations. First, since the study was a single-center retrospective analysis, biases may exist. Prospective studies will be needed to confirm our results. Second, the sample size was relatively small due to the rarity of inguinal LN metastasis from rectal or anal canal adenocarcinoma, although the number of patients who underwent inguinal dissection represented the largest sample reported to date. Third, treatment regimens varied among patients after inguinal LN dissection. Further prospective studies will be needed to confirm that inguinal LN metastasis from both rectal and anal canal adenocarcinoma is regional rather than distant.

\section{Conclusion}

Based on the acceptable prognosis of patients who underwent inguinal $\mathrm{LN}$ dissection with curative intent, the presence of inguinal metastasis in patients with lower rectal and anal canal adenocarcinoma can be considered regional LN metastasis. If $\mathrm{R} 0$ resection can be achieved, inguinal LN dissection may be indicated in patients with inguinal LN metastasis from both rectal and anal canal adenocarcinoma.

\section{Abbreviations}

AIC: Akaike Information Criterion; AJCC: American Joint Committee on Cancer; Cl: confidence interval; HR: hazard ratio; LLND: lateral lymph node dissection; LN: lymph node; NCCN: National Comprehensive Cancer Network; OS: Overall survival; TNM classification: Tumor-node-metastasis classification

\section{Acknowledgements}

The authors thank former staff members of our division, Moriya M., Akasu T., Fujita S., Yamamoto S., and Ochiai H. The authors thank Izawa J for his helpful advice on the statistical methods. And the authors thank all colleagues and nurses who provided patient care.

\section{Authors' contributions}

$\Pi T$ and $Y K$ designed the study. SK and YN reviewed statistical analyses and critically revised the manuscript. TT, ST and YK collected the data and performed the treatments. DS convinced of the study, and participated in its design and coordination. DS were responsible for writing the paper and for its supervision. All authors read and approved the final manuscript.

\section{Funding}

None.

\section{Availability of data and materials}

All data generated or analyzed during this study are included in this published article.

\section{Ethics approval and consent to participate}

This retrospective study was approved by the Institutional Review Board (IRB) of the National Cancer Center Hospital (IRB code: 2017-437). It was determined to be a retrospective analysis of de-identified data, and was determined to be exempt from requiring written informed consent.

Consent for publication

Not applicable.

\section{Competing interests}

The authors declare that they have no competing interests.

\section{Author details}

${ }^{1}$ Department of Colorectal Surgery, National Cancer Center Hospital, 5-1-1 Tsukiji, Chuo-ku, Tokyo 1040045, Japan. ${ }^{2}$ Division of Biomedical Statistics, Department of Integrated Medicine, Graduate School of Medicine, Osaka University, Osaka, Japan.

Received: 30 September 2018 Accepted: 18 July 2019

Published online: 24 July 2019

\section{References}

1. UICC. TNM classification of malignant tumours seventh edition. New York: Wiley-Blackwell, Ltd; 2009.

2. UICC. TNM classification of malignant tumours eighth edition. New York: John Wiley \& Sons, Ltd; 2017.

3. Shida D, Kanemitsu Y, Hamaguchi T, Shimada Y. Introducing the eighth edition of the tumor-node-metastasis classification as relevant to colorectal cancer, anal cancer and appendiceal cancer: a comparison study with the seventh edition of the tumor-node-metastasis and the Japanese classification of colorectal, Appendiceal, and anal carcinoma. Jpn J Clin Oncol. 2019;49(4):321-8.

4. Gunderson LL, Moughan J, Ajani JA, Pedersen JE, Winter KA, Benson AB 3rd, Thomas CR Jr, Mayer RJ, Haddock MG, Rich TA, et al. Anal carcinoma: impact of TN category of disease on survival, disease relapse, and colostomy failure in US gastrointestinal intergroup RTOG 98-11 phase 3 trial. Int J Radiat Oncol Biol Phys. 2013;87(4):638-45.

5. Wang R, Wu P, Shi D, Zheng H, Huang L, Gu W, Xu Y, Cai S, Cai G. Risk factors of synchronous inguinal lymph nodes metastasis for lower rectal cancer involving the anal canal. PLoS One. 2014;9(11):e111770.

6. Gerard JP, Chapet O, Samiei F, Morignat E, Isaac S, Paulin C, Romestaing P, Favrel V, Mornex F, Bobin JY. Management of inguinal lymph node metastases in patients with carcinoma of the anal canal: experience in a series of 270 patients treated in Lyon and review of the literature. Cancer. 2001;92(1):77-84.

7. Islami F, Ferlay J, Lortet-Tieulent J, Bray F, Jemal A. International trends in anal cancer incidence rates. Int J Epidemiol. 2017;46(3):924-38.

8. Su Z, Guo ZW, Mao YP, Tang J, Lan XW, Xie FY, Li Q. Anal adenocarcinoma requires prophylactic inguinal nodal treatment: results from a single Chinese institution. J Cancer. 2017:8(6):1097-102.

9. Tocchi A, Lepre L, Costa G, Liotta G, Mazzoni G, Agostini N, Miccini M. Rectal cancer and inguinal metastases: prognostic role and therapeutic indications. Dis Colon Rectum. 1999:42(11):1464-6.

10. Hamano T, Homma Y, Otsuki Y, Shimizu S, Kobayashi H, Kobayashi Y: Inguinal lymph node metastases are recognized with high frequency in rectal adenocarcinoma invading the dentate line. The histological features at the invasive front may predict inguinal lymph node metastasis. Colorectal Dis 2010, 12 (10 Online):e200-e205.

11. Luna-Perez P, Corral P, Labastida S, Rodriguez-Coria D, Delgado S. Inguinal lymph node metastases from rectal adenocarcinoma. J Surg Oncol. 1999;70(3):177-80

12. Bardia A, Greeno E, Miller R, Alberts S, Dozois E, Haddock M, Limburg P. Is a solitary inguinal lymph node metastasis from adenocarcinoma of the rectum really a metastasis? Color Dis. 2010;12(4):312-5.

13. Adachi $\mathrm{T}$, Hinoi $\mathrm{T}$, Egi $\mathrm{H}$, Ohdan $\mathrm{H}$. Surgical treatment for isolated inguinal lymph node metastasis in lower rectal adenocarcinoma patients improves outcome. Int J Color Dis. 2013;28(12):1675-80.

14. Benson AB 3rd, Venook AP, Al-Hawary MM, Cederquist L, Chen YJ, Ciombor KK, Cohen S, Cooper HS, Deming D, Engstrom PF, et al. Rectal Cancer, version 2.2018, NCCN clinical practice guidelines in oncology. J Natl Compr Cancer Netw. 2018;16(7):874-901.

15. Benson AB 3rd, Venook AP, Al-Hawary MM, Cederquist L, Chen YJ, Ciombor KK, Cohen S, Cooper HS, Deming D, Engstrom PF, et al. Anal carcinoma, version 2.2018, NCCN clinical practice guidelines in oncology. J Natl Compr Cancer Netw. 2018;16(7):852-71.

16. Sauer R, Becker H, Hohenberger W, Rodel C, Wittekind C, Fietkau R, Martus $P$, Tschmelitsch J, Hager E, Hess CF, et al. Preoperative versus postoperative chemoradiotherapy for rectal cancer. N Engl J Med. 2004;351(17):1731-40.

17. Watanabe T, Muro K, Aijioka Y, Hashiguchi Y, Ito Y, Saito Y, Hamaguchi T, Ishida H, Ishiguro M, Ishihara S, et al. Japanese Society for Cancer of the 
Colon and Rectum (JSCCR) guidelines 2016 for the treatment of colorectal cancer. Int J Clin Oncol. 2018;23(1):1-34.

18. Greenland S, Mansournia MA, Altman DG. Sparse data bias: a problem hiding in plain sight. BMJ. 2016;352:1981.

19. H A: A new look at the statistical model identification. . IEEE Trans Autom Control 1974, 19:716-723.

20. Graham RA, Hohn DC. Management of inguinal lymph node metastases from adenocarcinoma of the rectum. Dis Colon Rectum. 1990;33(3):212-6.

21. Franko J, Shi Q, Meyers JP, Maughan TS, Adams RA, Seymour MT, Saltz L, Punt CJA, Koopman M, Tournigand C, et al. Prognosis of patients with peritoneal metastatic colorectal cancer given systemic therapy: an analysis of individual patient data from prospective randomised trials from the analysis and research in cancers of the digestive system (ARCAD) database. Lancet Oncol. 2016;17(12):1709-19.

22. Morris EJ, Forman D, Thomas JD, Quirke P, Taylor EF, Fairley L, Cottier B, Poston G. Surgical management and outcomes of colorectal cancer liver metastases. Br J Surg. 2010;97(7):1110-8.

23. Jones RP, Kokudo N, Folprecht G, Mise Y, Unno M, Malik HZ, Fenwick SW, Poston GJ. Colorectal liver metastases: a critical review of state of the art. Liver Cancer. 2016;6(1):66-71.

24. Shida D, Tsukamoto S, Ochiai H, Kanemitsu Y. Long-term outcomes after RO resection of synchronous peritoneal metastasis from colorectal Cancer without Cytoreductive surgery or Hyperthermic intraperitoneal chemotherapy. Ann Surg Oncol. 2018;25(1):173-8.

25. Shida D, Yoshida T, Tanabe T, Tsukamoto S, Ochiai H, Kanemitsu Y. Prognostic impact of RO resection and targeted therapy for colorectal Cancer with synchronous peritoneal metastasis. Ann Surg Oncol. 2018;25(6):1646-53.

26. Lengele B, Scalliet P. Anatomical bases for the radiological delineation of lymph node areas. Part III: pelvis and lower limbs. Radiother Oncol. 2009;92(1):22-33.

27. Grinnell RS. The lymphatic and venous spread of carcinoma of the rectum. Ann Surg. 1942;116(2):200-16.

\section{Publisher's Note}

Springer Nature remains neutral with regard to jurisdictional claims in published maps and institutional affiliations.

Ready to submit your research? Choose BMC and benefit from:

- fast, convenient online submission

- thorough peer review by experienced researchers in your field

- rapid publication on acceptance

- support for research data, including large and complex data types

- gold Open Access which fosters wider collaboration and increased citations

- maximum visibility for your research: over $100 \mathrm{M}$ website views per year

At $\mathrm{BMC}$, research is always in progress.

Learn more biomedcentral.com/submissions 